\title{
Synergy between synthetic aperture radar and other sensors for the remote sensing of the ocean
}

\author{
Susanne UFERMANN, Ian S. ROBINSON, José C.B. DA SILVA \\ School of Ocean and Earth Science \\ Southampton Oceanography Centre \\ European Way \\ Southampton SO14 3ZH \\ United Kingdom \\ Email: ufermann@,soton.ac.uk \\ http://www.soton.ac.uk/ ufermann \\ Instituto de Oceanografia \& Dept. de Fisica \\ Faculdade de Ciências da Universidade de Lisboa \\ Rua Ernesto de Vasconcelos \\ Campo Grande \\ 1700 Lisboa \\ Portugal.
}

\begin{abstract}
Over the last decades, satellite remote sensing has proved to be a valuable and effective tool for monitoring physical and biological ocean processes. However there are cases where data from one remote sensor alone cannot be interpreted unambiguously. In these situations the combination of data from different sensors can help to understand the observed processes due to the combined benefits of the various strengths and advantages of individual instruments. This paper illustrates the potential of synergy between synthetic aperture radar data and data from thermal and optical satellite sensors. Different aspects of oceanic and atmospheric fronts, eddies, upwelling, internal waves and surface films are imaged by the sensors and combined data give a broader picture of the physical processes involved. While the strengths of synergy are demonstrated in several examples, more frequent coincidence of data from existing and future sensors will be necessary before the benefits of synergy occur on an operational basis.
\end{abstract}




\section{INTRODUCTION}

The monitoring of the sea surface by synthetic aperture radar (SAR) from space has made enormous progress over the last decades so that today a variety of oceanic processes can be identified with a high degree of confidence from SAR images alone. However there remain cases where SAR signatures are ambiguous and additional information is needed to interpret an image. Since it is usually difficult to find simultaneously acquired in-situ data, the easiest approach to this problem is to use satellite data from other sensors to assist the image analysis. By this means, the advantages of each data type can be combined while some of the disadvantages of one sensor can be compensated for by the benefits of another. Some important measurement characteristics in this context are spatial resolution, sensitivity to atmospheric processes (e.g. cloud cover), swath width of the sensor, comprehensiveness of the measured property and accuracy.

Whilst the previous four papers in this issue have highlighted the strengths of SAR imaging for a variety of processes, this paper investigates ways in which data from other sensors can assist the interpretation of SAR images in those cases where the radar signatures alone do not allow unambiguous interpretation. Strengths and weaknesses of the individual data types are identified, and benefits as well as problems in their combination with SAR data are explained. We then use some examples to demonstrate in detail how various phenomena are monitored by different remote sensors and how this information can be exploited to interpret simultaneously acquired SAR data. 


\section{DATA}

As well as SAR, the additional data used for this study have been acquired by thermal and optical sensors. The following paragraphs give an overview of these data types and their advantages and disadvantages. A summary of properties of sensors and data used in this study is given in Table 1 .

\section{Thermal Data}

Sensors measuring the sea surface temperature (SST) detect the radiation emitted from the sea surface in the infrared waveband (approx. 0.6-12.5 $\mu \mathrm{m}$ ). It is important to note that only the top $0.1 \mathrm{~mm}$ of the water column contribute to this measurement which is why this property is often referred to as skin temperature of the ocean. This is in contrast to the traditional oceanographic understanding of SST which is usually measured at a few $\mathrm{cm}$ to a few $m$ depth and commonly called bulk temperature. Not only can the difference between skin and bulk temperature be up to $1^{\circ} \mathrm{K}$ (Schlüssel, 1990), the skin temperature of the ocean can also change over very short time scales in the order of seconds (Donlon, 1994). Some mesoscale phenomena such as fronts, eddies and upwelling are known to be visible in both SAR and SST images. It is not immediately obvious which mechanism is responsible for this correlation. Possibilities include a direct relationship between surface roughness and the SST through an influence of the stability of the atmospheric boundary layer, or dynamical structures which also cause temperature patterns (Johannessen et al., 1996; Robinson and Johannessen, 1997). Other processes, like e.g. internal waves, local variability of surface winds and flow over shallow bathymetry which are visible in SAR imagery do not necessarily produce a temperature signal (Alpers, 1985, Gower, 1993). 
SST data used for comparison with SAR images has been acquired by either the Advanced Very High Resolution Radiometer (AVHRR) aboard the NOAA satellites or the Along-Track Scanning Radiometer (ATSR) aboard the European Remote Sensing satellite (ERS). Both instruments have a maximum spatial resolution of $1.1 \times 1.1 \mathrm{~km}^{2}$ at nadir and compare equally well with in-situ temperature measurements $\left(0.12^{\circ} \mathrm{K} \pm 0.17^{\circ} \mathrm{K}\right.$ for AVHRR (Kearns et al., 2000), $0.16^{\circ} \mathrm{K} \pm 0.37^{\circ} \mathrm{K}$ for ATSR (Merchant and Harris, 1999)) with a relative sensitivity of approximately $0.05^{\circ} \mathrm{K}$ for ATSR and $0.1^{\circ} \mathrm{K}$ for AVHRR. However, due to a larger swath width of $2399 \mathrm{~km}$ compared to $512 \mathrm{~km}$ for ATSR, only AVHRR achieves daily global coverage.

Generally, it can be said that the resolution of recent SST sensors is poorer than that of SAR by between one and two orders of magnitude. In addition to that, SST data can only be recorded under cloud free conditions as the radiation detected by the sensor cannot penetrate clouds. These disadvantages of SST data are balanced by better coverage with a higher repeat frequency and the fact that often SST is a very comprehensive quantity that clearly distinguishes between different water bodies and therefore provides good insights into physical processes at the sea surface.

\section{Optical Data}

Sensors used to monitor the colour of the ocean detect the radiation emitted by the sea surface at visible and infrared wavelengths (approx. 0.4-0.9 $\mu \mathrm{m}$ ). By using a correction for the influence of the atmosphere, the water leaving radiances can be retrieved and used for the derivation of concentrations of optically active (i.e. absorbing and/or scattering) substances in the water such as chlorophyll. This processing chain is carried out on an operational basis and works well for those waters that are optically relatively simple and 
well understood. These are usually open ocean waters whose only optically active substances are phytoplankton and its decay products (case-I waters). However, in coastal regions the proximity of the land complicates the situation as other optically active material like yellow substance and suspended particulates enter the water (case-II waters) and cause both the atmospheric correction and the methods for the derivation of chlorophyll to fail. Recent research investigates the possibilities of applying specially developed algorithms for these waters for the derivation of accurate measures of water leaving radiance as well as concentrations of the substances in the water (see e.g. Hu et al., 2000; Ruddick et al, 2000, Ufermann et al., 2000). At this stage however, chlorophyll concentration maps that are derived from ocean colour measurements in coastal areas need to be considered with some care. Whilst they may provide an overview of processes in the region, the quantitative information they contain is somewhat limited.

Ocean colour data used for this study has been acquired by the Sea-viewing Wide Field-of-view Sensor (SeaWiFS). Data from other sensors are available and might be used in future, in particular data acquired by the Medium Resolution Imaging Spectrometer (MERIS) aboard Envisat which will be launched in autumn 2001. The maximum spatial resolution of SeaWiFS data is $1.1 \times 1.1 \mathrm{~km}^{2}$ at nadir. Accuracy goals for the sensor at launch were $5 \%$ for water-leaving radiances and $35 \%$ for chlorophyll concentration (Hooker et al., 1992). These are met by the sensor in case-I water conditions (McClain et al., 1998). SeaWiFS provides global coverage at $4.5 \mathrm{~km}$ nadir resolution.

Ocean colour data have limitations and advantages similar to SST data when compared to SAR data: their resolution is significantly lower and the acquisition depends on cloud free conditions. However, a much higher sampling rate achieved by a larger swath width and the comprehensiveness of the measured quantity compensate for these disadvantages. 
Figure 1 gives an overview of the different sampling characteristics of the thermal and visible sensors used in this study together with ERS SAR with regard to some oceanographic phenomena. It shows that there is a negative correlation between the space and time sampling capacities of the different sensors. It is this fact that makes the combination of data from different sensors so beneficial as SARs low temporal and high spatial coverage are balanced by a much better temporal coverage with less spatial detail from the other sensors. It is also shown that the combination of data from thermal and visible sensors alone improves the temporal coverage through a higher combined sampling rate. This is an important improvement as temporal coverage is often a limiting factor in satellite oceanography. It becomes obvious that an optimum coverage of oceanographic phenomena in time and space can only be achieved through combination of all different data types thus accounting for phenomena occurring in the temporal range of hours to years and extending over areas from a few tens of meters to thousands of kilometres.

\section{Data Processing}

The differences in spatial resolution between SAR and other sensors require some data processing procedures to enable an effective comparison of individual signatures. For most cases, the SAR resolution of $25 \mathrm{~m}$ is not required for the observation of mesoscale processes. Furthermore, reducing the resolution of the SAR images reduces speckle and can thus enhance certain signatures of oceanic processes. Therefore, most of the SAR images shown in this work have been reduced to $512 \times 512$ pixels of $200 \times 200 \mathrm{~m}^{2}$ derived as root mean squares of $16 \times 16$ original pixels (considering amplitude images). Images from other sensors were then mapped onto the same $200 \mathrm{~m}$ resolution grid as the SAR 
images (see individual figure captions for detailed information). All of the SAR images were corrected for effects of the sensor's incidence angle which otherwise produces a trend of decreasing backscatter with increasing range

\section{ATMOSPHERIC PHENOMENA}

Since atmospheric processes generally do not affect the radiation emitted by a SAR, they can only be observed in SAR images where they interact with the sea surface and modulate its roughness patterns. Examples for such processes are atmospheric fronts with different wind speeds on either side of the front, intense low pressure systems, atmospheric gravity and lee waves, convective processes like atmospheric boundary layer rolls or atmospheric convective cells and rain cells. It has been demonstrated in the past that all of these phenomena can be observed by SAR and information on wind speed, stratification and height of the marine atmospheric boundary layer can be obtained by analysing the SAR images alone (Mitnik, 1992; Vachon et al., 1995; Johannessen et al., 1996; Sikora et al., 1997; Melsheimer et al., 1998; Ufermann and Romeiser, 1999; Vachon et al., 2000; Young et al., 2000).

But there are cases where it can be difficult without further information to confidently determine whether the origin of a SAR signature is either oceanic or atmospheric. In these situations, additional data from other sensors can be very helpful for the interpretation of the radar image. Under such circumstances it can sometimes even be an advantage that optical and thermal sensors cannot see through clouds as they can thus convey a direct image of processes in the atmosphere. In addition to this, both of these sensors clearly distinguish between different water masses due to their thermal and optical properties. Figure 2 shows an example of such a case. The upper panel consists of two SAR 
images that were acquired by the European Remote Sensing satellite 2 Synthetic Aperture Radar (ERS-2 SAR). The image on the left hand side was acquired on October 16, 1995, at 14:00 UTC, south of the Patagonian shelf and shows the entrance to the Magellan Strait in the bottom left corner. The image on the right hand side was acquired on October 20, 1995, at 13:34 UTC, south of the Falkland Islands.

Both images show frontal, line-like signatures that could originate from either oceanic or atmospheric processes: in the SAR image (a), two signatures can be found in the southwestern (i.e. the bottom left) corner of the image (one with a E-W orientation, the other one with a SW-NE orientation) and another one in the northeastern (i.e. top right) corner of the image (oriented E-W). The SAR image in (b) shows a frontal signature with a SW-NE orientation on the eastern (i.e. right) side of the scene. The signatures show similar backscattering characteristics in shape and magnitude and length scales of approximately $15-25 \mathrm{~km}$. Based on this information alone, it is therefore impossible to decide whether these signatures were caused by atmospheric or oceanic processes.

The bottom panel of Figure 2 shows derived SST images acquired by ATSR on October 16, 1995, at 14:30 UTC and October 20, 1995, at 14:04 UTC respectively. Both images have been re-sampled to match the area depicted in the corresponding SAR scenes. The ATSR image in (c) acquired just 30 minutes from (a) clearly shows two areas of warmer waters, one towards the South-West and the other one towards the North-East. The boundaries of both warm water bodies coincide with the frontal signatures in the SAR images. Therefore it seems very likely that the SAR signatures were caused by wavecurrent interaction originating from frontal processes between the two different water masses. No information on atmospheric processes can be derived from this ATSR image.

In contrast to this, the ATSR at (d) shows distinctly different signatures. While it also depicts a warmer water mass towards the North-West separated from a colder water mass 
towards the South-East (bottom right corner of the image), the boundary between the two does not seem to correspond to the observed SAR signature at all. However, the location where the SAR image shows a frontal signature is in line with a band of clouds visible in the ATSR image (black areas). The surrounding pixels of SST all show very similar values indicating little oceanic activity in the area. As mentioned before, clouds are likely to occur in areas of atmospheric change, i.e. especially in frontal zones. Therefore it seems reasonable to assume that the SAR signature has been caused by an atmospheric rather than an oceanic front.

Figure 3 shows a set of images acquired on November 9, 1995, at (a) 13:08 UTC and (b) 13:38 UTC in the area of the southern Magellan Strait. The SAR image shows a distinct mottled pattern on the left hand side. Even though this pattern is known to originate from atmospheric convective cells (Mitnik, 1992, Ufermann and Romeiser, 1999) it is interesting to note that the ATSR image shows signatures of clouds in the corresponding region.

Atmospheric convective cells develop in areas where the thermal stratification of the marine atmospheric boundary layer is unstable, i.e. the temperature of the sea surface is higher than that of the lowest layers of the atmosphere. A strong vertical transport of air, heat and humidity is associated with these cells and they often create clouds with a mottled structure similar to the one visible in both the SAR and the ATSR image. Also those pixels surrounding the cloud signatures in the ATSR image exhibit a higher temperature than the surrounding pixels. This means that the localised appearance of atmospheric convective cells is most likely due to a locally higher SST that might just exceed the air temperature in that area and therefore create unstable conditions of the marine atmospheric boundary layer only in this region. 


\section{CURRENTS AND FRONTAL FEATURES}

Once it has been established that a SAR signature originates from an oceanic rather than an atmospheric phenomenon, synergy with data from other sensors can help to understand the physical processes involved in creating the observed signatures. Figure 4 shows an example of such a situation. The ERS-2 SAR image on the was acquired on May 18,1998 , at 10:40 UTC in the southern North Sea. It shows elongated signatures along the centre of the image that could be caused by either current variations due to fronts or bottom topography. The right hand side of Figure 4 shows a derived SST image acquired by AVHRR three hours after the SAR image. It depicts a coastal warm-water jet originating from the mouth of the river Rhine which is just south of the imaged area. Comparing the outline of this warm water jet with the SAR signatures shows that they coincide very well thus leading to the conclusion that the elongated SAR signatures are caused by wavecurrent interaction at the front between the North Sea waters and the freshwater plume. The higher temperatures near the coast could also explain the generally higher return in the corresponding area of the SAR image as they create a weaker stratification of the marine atmospheric boundary layer compared to the surrounding region (assuming a relatively constant temperature in the atmosphere).

The ERS-2 SAR image shown in Figure 5a shows a similar setting: the coastline towards the East (i.e. right hand side of the image) is the south-western tip of Portugal, strong frontal signatures can be observed $20-40 \mathrm{~km}$ off the coast. But in this case, the waters near the coast exhibit a lower backscatter signal compared to the surrounding waters. This corresponds to an area of relatively cold water visible near the coast in the AVHRR image in Figure 5b which is caused by upwelling of the deeper and therefore colder waters. Thus, the frontal signatures in the SAR image are caused by the interaction 
of the two different water masses. It is not immediately clear though what is causing the generally low radar return near the coast. One possible explanation is the larger stability of the marine atmospheric boundary layer in this region due to the lower temperature of the sea surface, i.e. the inverse of the effect observed in the previous example where the warmer coastal waters gave a generally higher radar return. Another possible explanation is that the upwelling leads to an increase in nutrient supply near the coast and therefore an increase in primary production. This, in turn, could then lead to accumulation of natural surface films in the area which would dampen the surface waves responsible for the radar backscatter. A SeaWiFS image acquired in the same region on that day (not shown) confirms that there has been increased primary production in the upwelling region. A third explanation is wind shadowing by the land. This hypothesis seems to be confirmed by both the increased radar backscatter in the south-eastern corner of the image which would be more exposed to winds coming from an easterly direction and the observed upwelling for which an easterly wind would create favourable conditions.

Another example is shown in Figure 6. The ERS SAR image on the left hand side has been acquired on October 7, 1995, at 11:29 UTC between Scotland and Iceland. Towards the lower right corner, the image shows a series of dark elongated signatures. A comparison with the ATSR image acquired over the same region at 11:58 UTC on October 7, 1995, shown on the right hand side of Figure 6 reveals that these signatures coincide with the boundary of a mesoscale eddy. Due to the wider swath width of the ATSR, the image also provides an overview of the large-scale physical situation. It shows that the eddy that has been monitored by SAR is part of a larger thermal front that extends over several hundreds of kilometres.

Figure 7 gives an example for a situation where although SAR and ATSR cannot directly detect the same phenomenon, the SST image assists the interpretation of the SAR 
image. The ERS SAR image on the left hand side has been acquired on October 9, 1995, at 12:06 UTC over the Iceland-Faeroes front. It shows a number of signatures originating from internal waves in the upper half of the image. The ATSR $11 \mu \mathrm{m}$ brightness temperature image on the right hand side shows a thermal front with its warm side on the southern side (i.e. the lower part of the image) and its colder side on the North (i.e. the upper part of the image). Even though there is no sign of the internal waves visible in the thermal image, the texture change observed in the SAR image seems to delineate the thermal front visible in the ATSR image. The internal wave signatures only occur in the area identified as the colder side of the front which suggests either that both the internal waves and the temperature front are caused or maintained by a common feature (e.g. bottom topography) or that the internal waves are directly influenced by the thermal processes in the region .

\section{SURFACE FILMS}

Surface films of either anthropogenic or natural origin can often be observed in SAR images (cite this issue and citations therein). Usually, it is possible to distinguish between these two with a fair degree of confidence due to the individual shape and size of a specific SAR signature. Therefore and due to low resolution of most thermal and optical sensors $(1.1 \mathrm{~km})$, synergy is unlikely to be of much practical use in distinguishing between natural and man-made surface films. However, for the monitoring of large scale natural surface films data from other sensors can often help to better understand the signatures observed in SAR images and to put them into a wider context of the processes in the imaged region. Figure 8 shows images of the Baltic proper, just East of the south-western Swedish coast. 
In this area, the regularly occurring blooms of nitrogen-fixing filamentous cyanobacteria (blue-green algae) are a well-known phenomenon that may cause problems for the local fisheries and tourism. Both images were acquired on July 28, 1999. The Radarsat SAR image on the left hand side shows signatures of natural surface films towards the bottom left. From the SAR image alone, although on the edge of the image, the phenomenon appears to be localised extending over an area of approximately $40 \mathrm{~km}$ in diameter. But the colour composite image derived from three SeaWiFS bands on the right hand side reveals that, in fact, the entire southern Baltic shows signatures of cyanobacteria accumulations. In cases like this data from a sensor with daily coverage is essential for the monitoring of the algal bloom and the importance of the wider swath exceeds that of spatial resolution by far. However, the fact that SeaWiFS (and other optical and thermal sensors) are weather dependent and thus only deliver data under cloud free conditions is still a problem, particularly at these high latitudes. Thus a combination of both types of data can offer a good solution with some guaranteed weather independent SAR coverage and some larger scale but less reliable optical data.

\section{DISCUSSION AND CONCLUSION}

We have demonstrated with a number of examples that synergy between SAR images and data from other satellite sensors can be a powerful tool for monitoring the ocean. The spatial coverage and different properties of data from sensors like AVHRR, ATSR and SeaWiFS helps the interpretation of SAR images which show signatures that are difficult to analyse on their own. Even in cases where the origin of a SAR signature is known, other data can set this information into a wider context and provide an overview of larger scale processes which the observed phenomenon is part of. The lower spatial 
resolution of most thermal and optical sensors compared to SAR is sufficient for these quantitative studies where their data is used mainly to assist the interpretation of SAR images since the length scale of the studied mesoscale phenomena usually is in the order of $10 \mathrm{~km}$ and therefore sufficiently exceeds the pixel size of most sensors.

One of the remaining problems is the fact that optical and thermal radiation cannot penetrate cloud which limits the amount of available data particularly at higher latitudes. Combined with the narrow swath and coverage of recent SAR sensors, this makes the acquisition of coincident data from several sensors rare. However, this is a known problem and has been taken into account during the design of future sensors: The wide swath ScanSAR mode of the ASAR on Envisat which will be launched in October 2001, will overlap with ocean colour images from the Medium Resolution Imaging Spectrometer (MERIS) also aboard Envisat, which promises to produce a larger amount of coincident images. Unfortunately, the Advanced Along-Track Scanning Radiometer (AATSR, aboard Envisat) will still only view near to nadir, and a match between SAR and infrared on the same sensor will not be available from other missions in the near future.

\section{Acknowledgements}

The authors would like to thank Martin Gade and Ove Rud for providing the images shown in Figure 8. ERS SAR and ATSR images were supplied by the European Space Agency (ESA) (AO3-177 for Figure 5). SeaWiFS and AVHRR images were received by the Dundee Satellite Receiving Station and processed by the Remote Sensing Data Analysis Service (RSDAS) at Plymouth Marine Laboratory. Data courtesy of the NASA SeaWiFS project and Orbital Science Corporation. 


\section{REFERENCES}

Alpers, W., Theory of radar imaging of internal waves, Nature, 314, 245-247, 1985.

Donlon, C.J., An investigation of the oceanic skin temperature deviation, $\mathrm{PhD}$ thesis, University of Southampton, U.K, 1994.

Gower, J.F.R., Wind and surface features in SAR images: The Canadian program, in Proc.

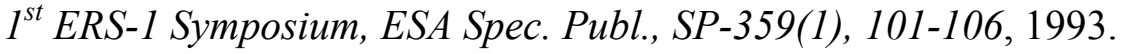

Hooker, S.B., W.E. Esaias, G.C. Feldman, W.W. Gregg and C.R. McClain, An Overview of SeaWiFS and Ocean Colour, in NASA Tech. Memo. 104566, Vol. 1, 1992.

Hu, C., K. Carder and F.E. Muller-Karger, Atmospheric correction of SeaWiFS imagery over turbid coastal waters: a practical method, Remote Sens. Environm., 74, $195-$ 206, 2000.

Kearns, E.J., J.A. Hanafin, R.H. Evans, P.J. Minnett and O.B. Brown, An independent assessment of Pathfinder AVHRR sea surface temperature accuracy using the Marine Atmosphere Emitted Radiance Interferometer (MAERI), Bulletin of American Meteorological Society, vol. 81(7), 2000.

McClain, C.R., M.L. Cleave, G.C. Feldman, W.W. Gregg, S.B. Hooker and N. Kuring, Science Quality SeaWiFS data for global biosphere research, Sea Technology, Sept. 1998, 10-16.

Melsheimer, C., W. Alpers and M. Gade, Investigation of multifrequency / multipolarization radar signatures of rain cells over the ocean using SIR-C/X-SAR data, J. Geophys. Research, 103, C9, 18,867-18,884, 1998.

Merchant, C.J., and A.R. Harris, Toward the elimination of bias in satellite retrievals of sea surface temperature 2. Comparison with in situ measurements, J. Geophys. Research, 104, 23 (C10), 23,579-23,590, 1999. 
Mitnik, L.M., Mesoscale coherent structures in the surface wind field during cold air outbreaks over the far eastern seas from satellite side looking radar, Mer, 30, $297-$ 314, 1992.

Robinson, I.S., and J. Johannessen, Opportunities for combined SAR and ATSR ocean observations during the ERS tandem mission, Proc. $3^{\text {rd }}$ ERS Symp. On Space at the service of our environment, Florence, Italy, pp. 1337-1342, 1997.

Ruddick, K.G., F. Ovidio and M. Rijkeboer, Atmospheric correction of SeaWiFS imagery for turbid coastal and inland waters, Appl. Optics, 39(6), 897-912, 2000.

Schlüssel, P., W.J. Emery, H. Grassl, T. Mammen, On the bulk-skin temperature difference and its impact on satellite remote sensing of sea surface temperature, J. Geophys. Research, 95, No. C8, 13,341-13,356, 1990.

Sikora, T.D., G.S. Young, H.N. Shirer and R.D. Chapman, Estimating convective atmospheric boundary layer depth from microwave radar imagery of the sea surface, J. Appl. Meteorol., 36, 833-845, 1997.

Ufermann, S., and R. Romeiser, Numerical study on signatures of atmospheric convective cells in radar images of the ocean, J. Geophys. Research, 104, C11, 25,707-25,719, 1999.

Ufermann, S., I.S. Robinson and C.D. Mobley, Investigations of case-II water optical properties in the Rhine region of freshwater influence, in Proceedings of Ocean Optics XV, Monaco, 2000.

Young, G.S., T.D. Sikora and N.S. Winstead, Inferring marine atmospheric boundary layer properties from spectral characteristics of satellite-borne SAR imagery, Monthly weather review, 128, 1506-1520, 2000. 


\begin{tabular}{|l|c|c|c|c|}
\hline & Property & $\begin{array}{c}\text { Spatial } \\
\text { resolution }\end{array}$ & Accuracy & Swath width \\
\hline ATSR & SST & $1.1 \mathrm{~km}$ & $\begin{array}{c}0.16^{\circ} \mathrm{K} \pm 0.37^{\circ} \mathrm{K} \\
\text { relative sensitivity } 0.05^{\circ} \mathrm{K}\end{array}$ & $512 \mathrm{~km}$ \\
\hline AVHRR & SST & $1.1 \mathrm{~km}$ at nadir & $\begin{array}{c}0.12^{\circ} \mathrm{K} \pm 0.17^{\circ} \mathrm{K} \\
\text { relative sensitivity } 0.1^{\circ} \mathrm{K}\end{array}$ & $2399 \mathrm{~km}$ \\
\hline SeaWiFS & $\begin{array}{l}\text { Ocean } \\
\text { colour }\end{array}$ & $1.1 \mathrm{~km}$ at nadir & $\begin{array}{c}5 \% \text { for water-leaving radiance, } \\
35 \% \text { for chlorophyll } \\
\text { concentration }\left(0.5-50.0 \mathrm{mg} / \mathrm{m}^{3}\right)\end{array}$ & $\begin{array}{c}2801 \mathrm{~km} \text { at } 1.1 \mathrm{~km} \text { resolution } \\
1502 \mathrm{~km} \text { at } 4.5 \mathrm{~km} \text { resolution }\end{array}$ \\
\hline
\end{tabular}

Table 1: Properties of sensors and data used in this study. 


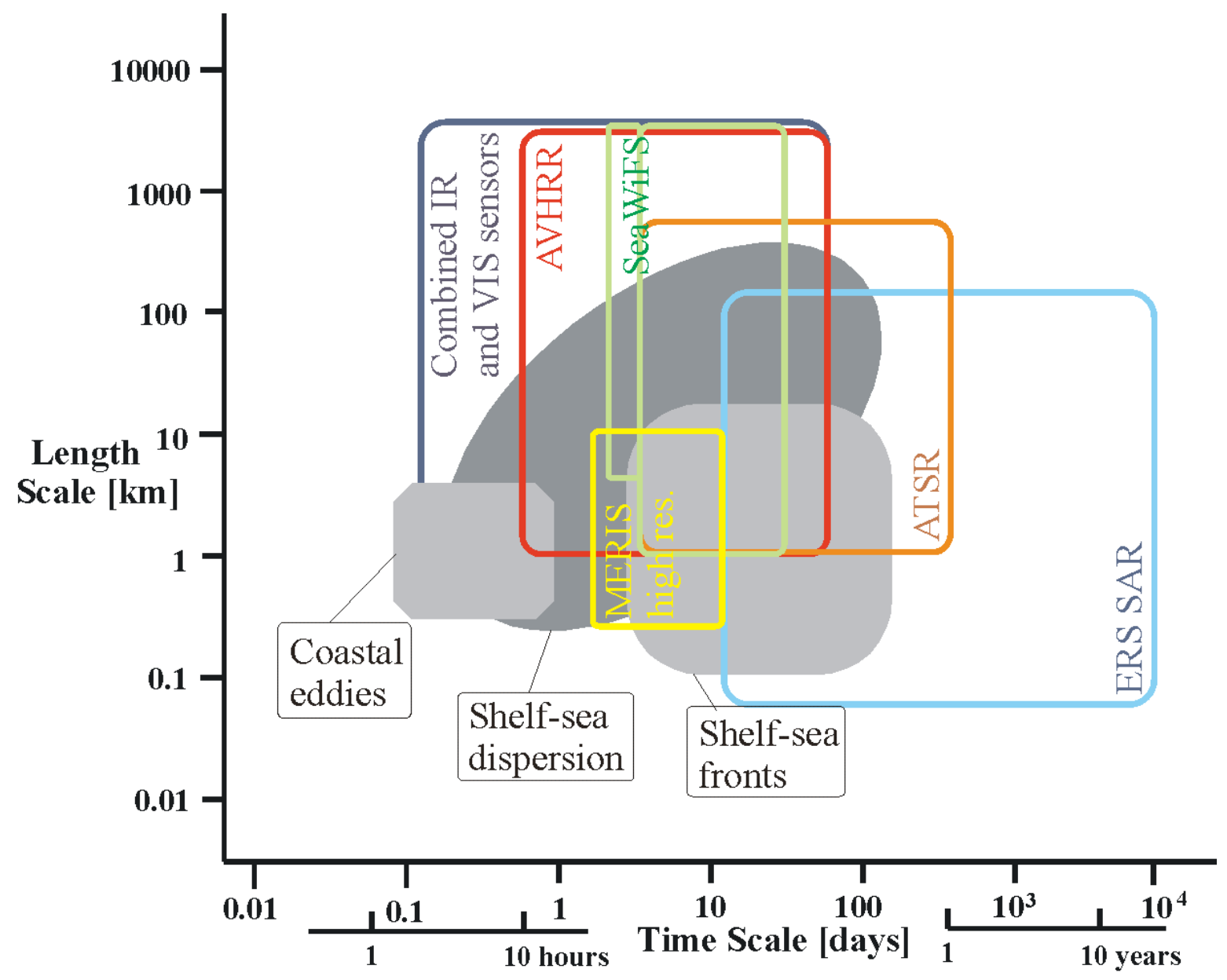

Figure 1: Sampling characteristics of several thermal infrared and visible sensors and ERS SAR for the monitoring of a number of coastal processes. 

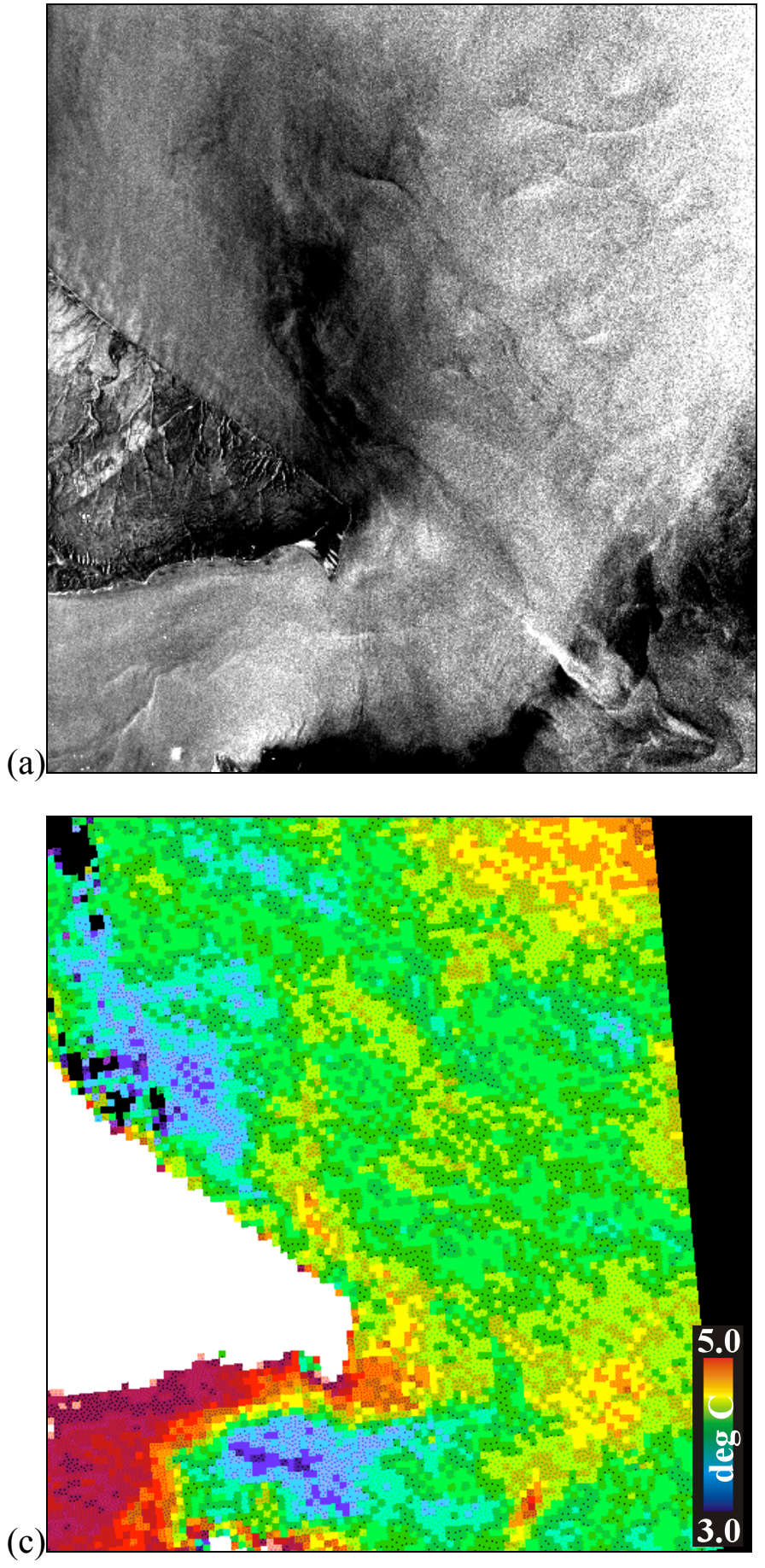

(b)

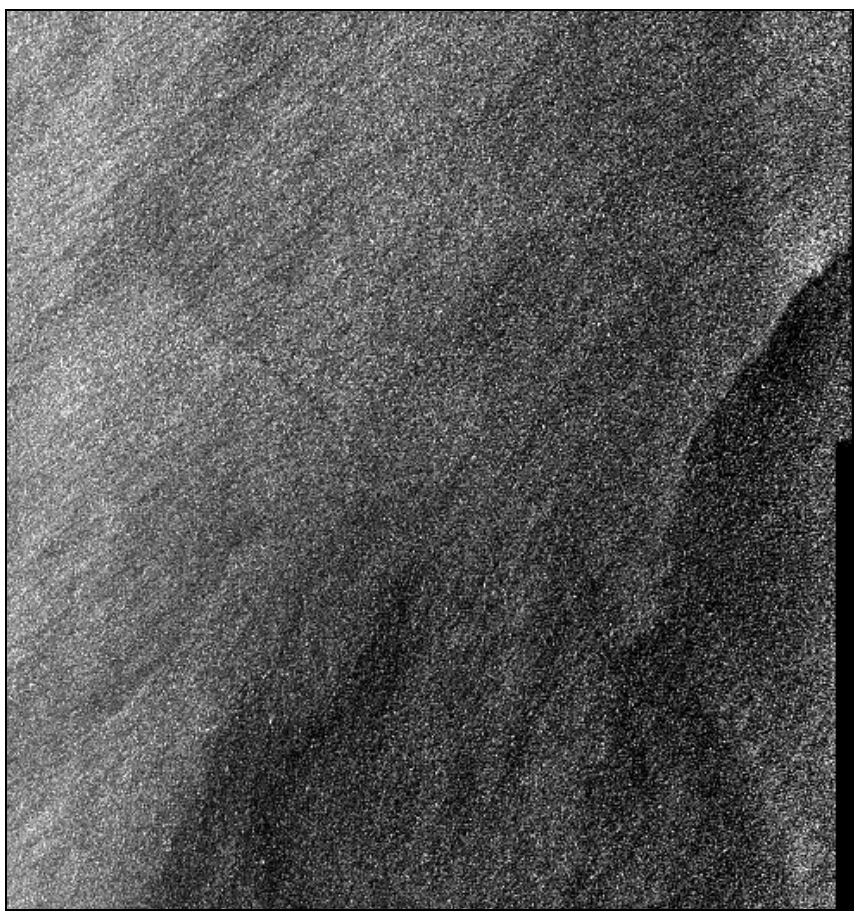

(d)

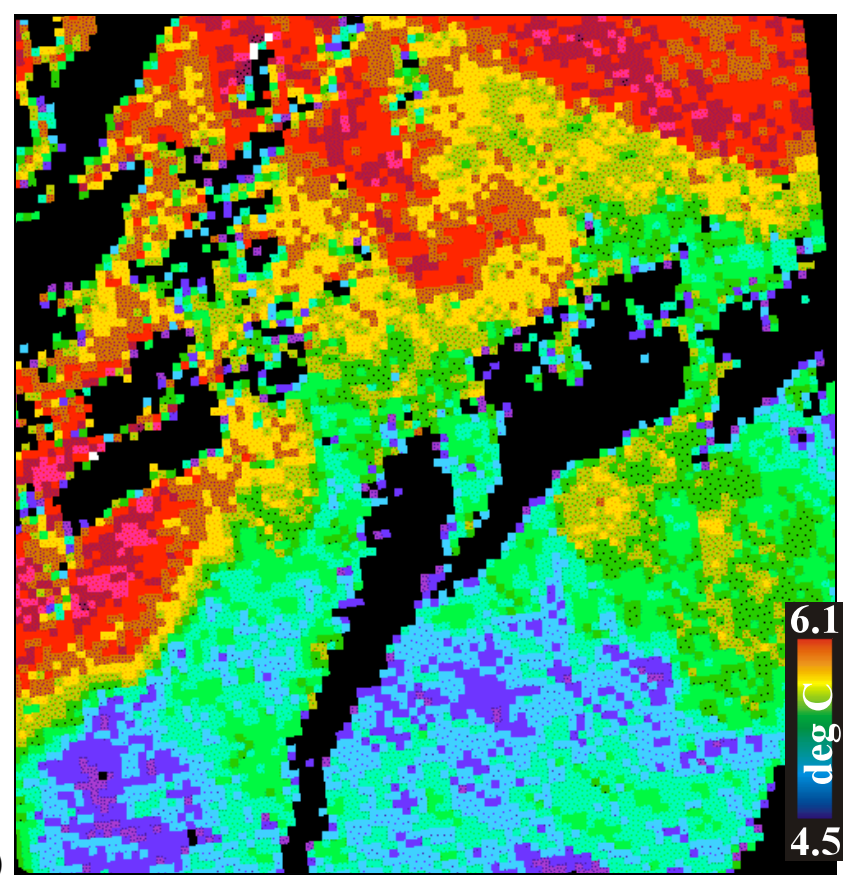

Figure 2: The size of all imaged areas is approximately $100 \times 100 \mathrm{~km}^{2}$ each. (a) ERS SAR image acquired on October 16, 1995, at 14:00 UTC south of the Patagonian Shelf $\left(67^{\circ} \mathrm{W}, 52^{\circ} \mathrm{S}\right)$; (b) ERS SAR image acquired on October 20, 1995, at 13:34 UTC south of the Falkland Islands $\left(63^{\circ} \mathrm{W}, 53^{\circ} \mathrm{S}\right)$; (c) ATSR derived SST image acquired on October 16, 1995, at 14:30 UTC showing the same area as (a); ATSR derived SST image acquired on October 20, 1995, at 14:04 UTC showing the same area as (b). 

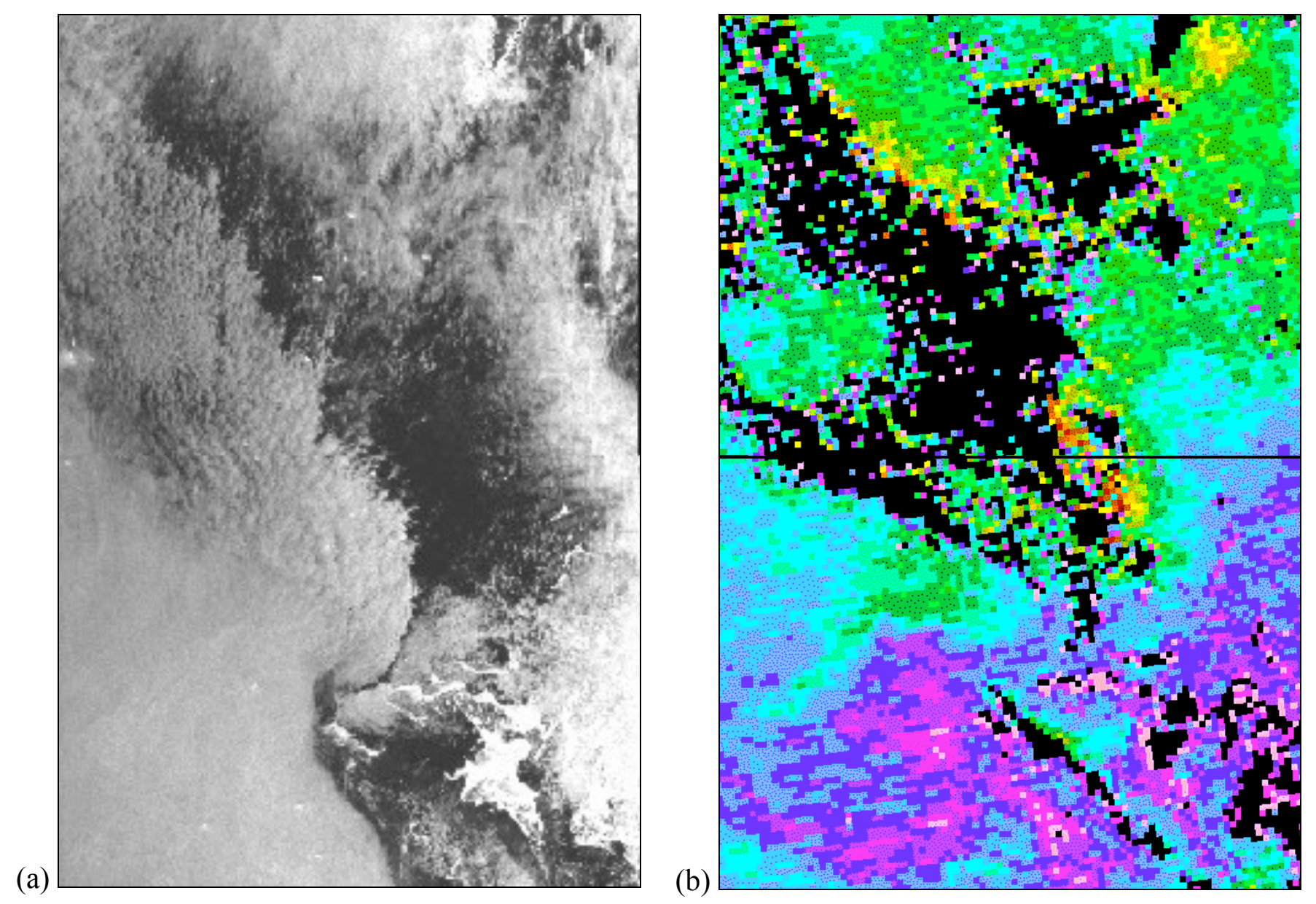

Figure 3: Images of the southern Magellan Strait near the Antarctic peninsula $\left(63^{\circ} \mathrm{S}, 63^{\circ} \mathrm{W}\right)$ acquired on November 9, 1995; size of the imaged area is approximately $100 \times 150 \mathrm{~km}^{2}$. (a) Composite of two ERS SAR images acquired at 13:08 UTC; (b) composite of two ATSR derived SST images acquired at 13:38 UTC. 
(a)

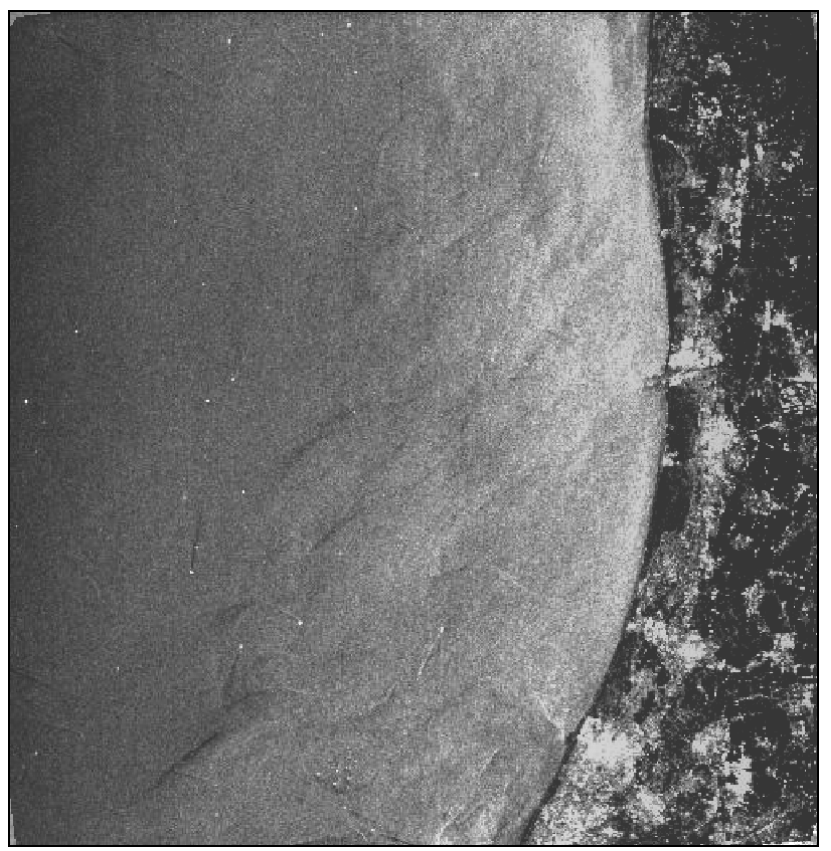

(b)

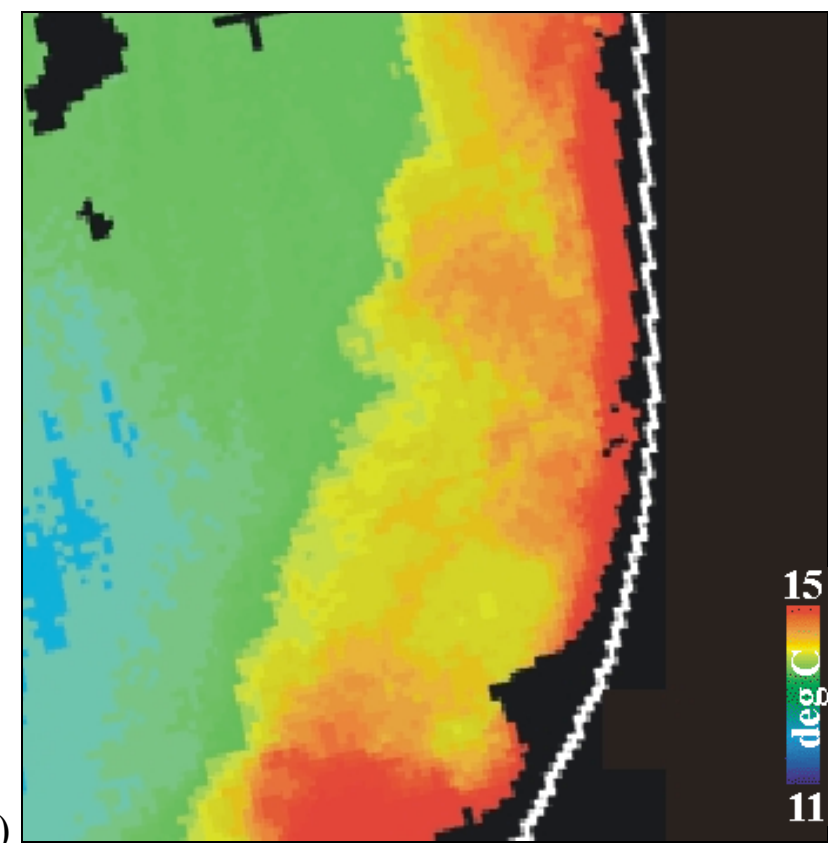

Figure 4: Images of the Southern North Sea $\left(52^{\circ} 30^{\prime} \mathrm{N}, 4^{\circ} 30^{\prime} \mathrm{E}\right)$ acquired on May 18, 1998; size of the imaged area is approximately $100 \times 100 \mathrm{~km}^{2}$. (a) ERS SAR image acquired at 10:40 UTC; (b) AVHRR derived SST image acquired at 13:30 UTC. 

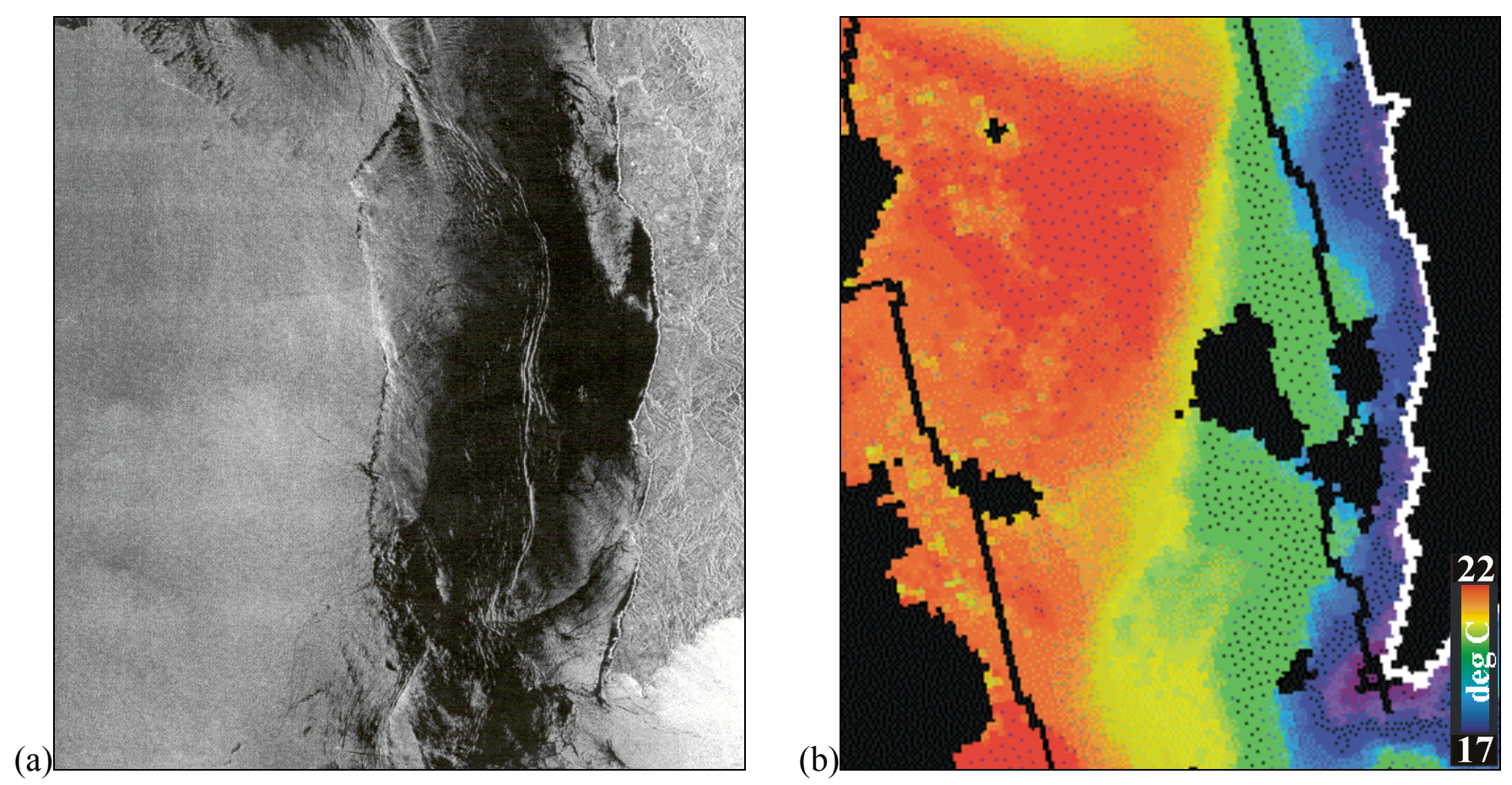

Figure 5: Images of the Iberian Shelf $\left(37^{\circ} \mathrm{N}, 9^{\circ} \mathrm{W}\right)$ acquired on September 3, 1999; size of the imaged area is approximately $100 \times 100 \mathrm{~km}^{2}$. (a) ERS SAR image acquired at 11:19 UTC; (b) AVHRR derived SST image acquired at 04:24 UTC. 

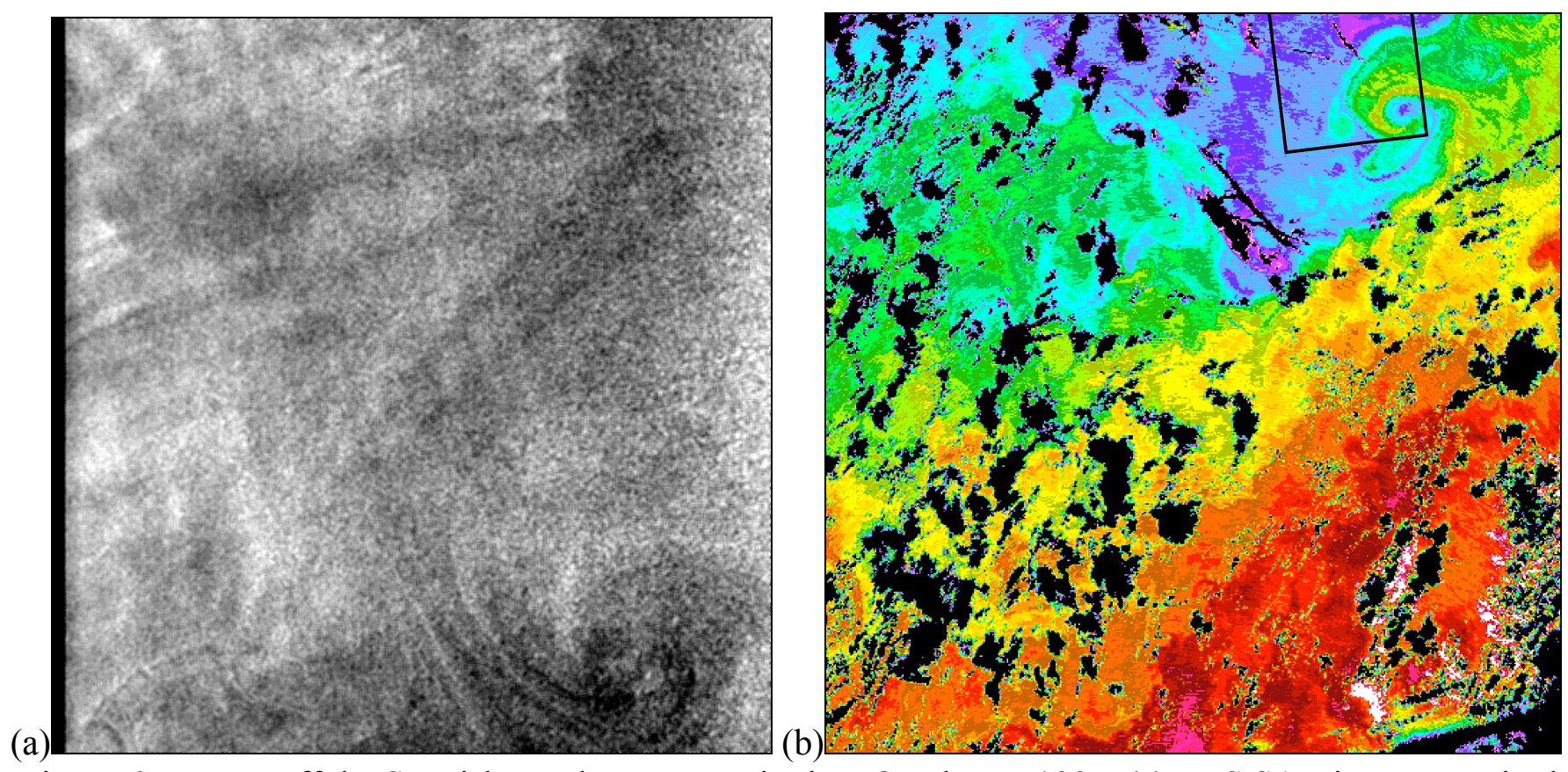

Figure 6: Images off the Scottish North coast acquired on October 7, 1995, (a) ERS SAR image acquired at 11:29 UTC, size of the imaged area: $100 \times 100 \mathrm{~km}^{2}$; (b) $11 \mu \mathrm{m}$ brightness temperature image acquired at 11:58 UTC, size of the imaged area: approximately $450 \times 450 \mathrm{~km}^{2}$. 
(a)

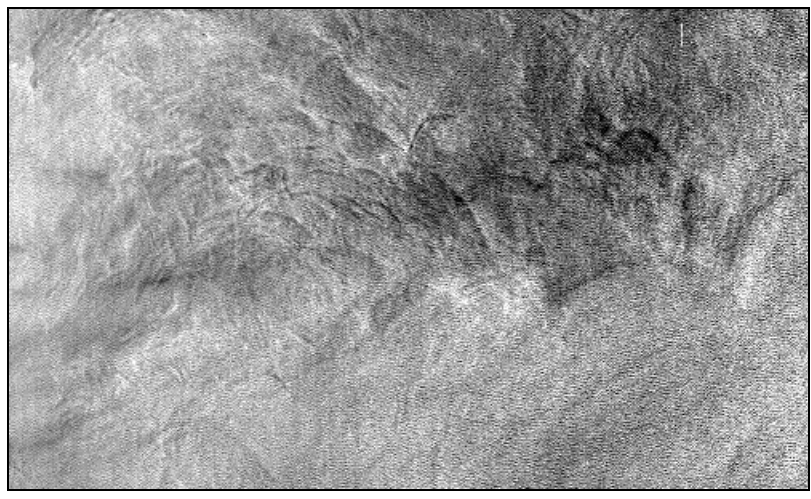

(b)

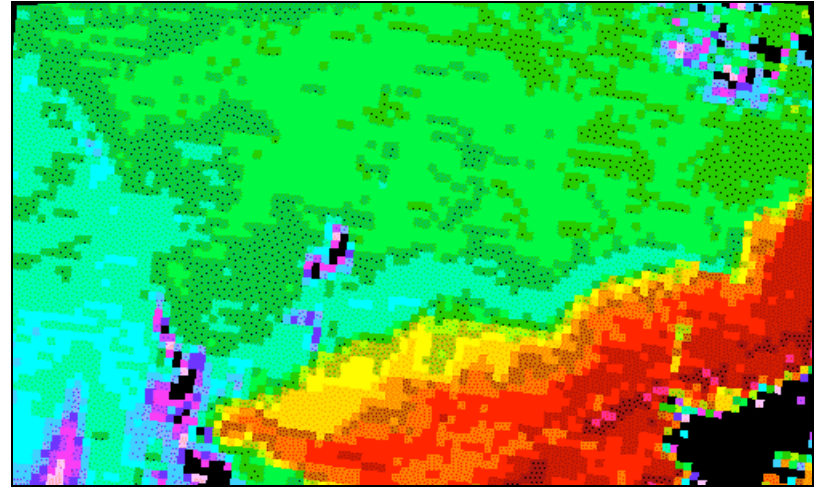

Figure 7: Images of the Iceland-Faeroer front acquired on October 9, 1995; size of imaged area: $100 \times 60$ $\mathrm{km}^{2}$; (a) ERS SAR image acquired at 12:06 UTC; (b) $11 \mu \mathrm{m}$ brightness temperature image acquired at 12:36 UTC. 
(a)

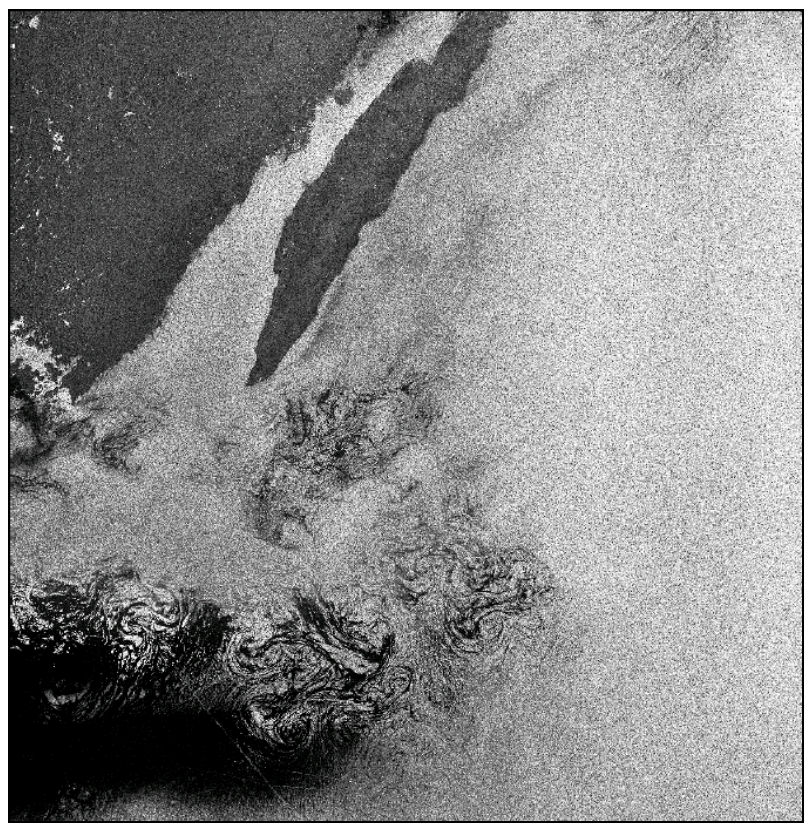

(b)

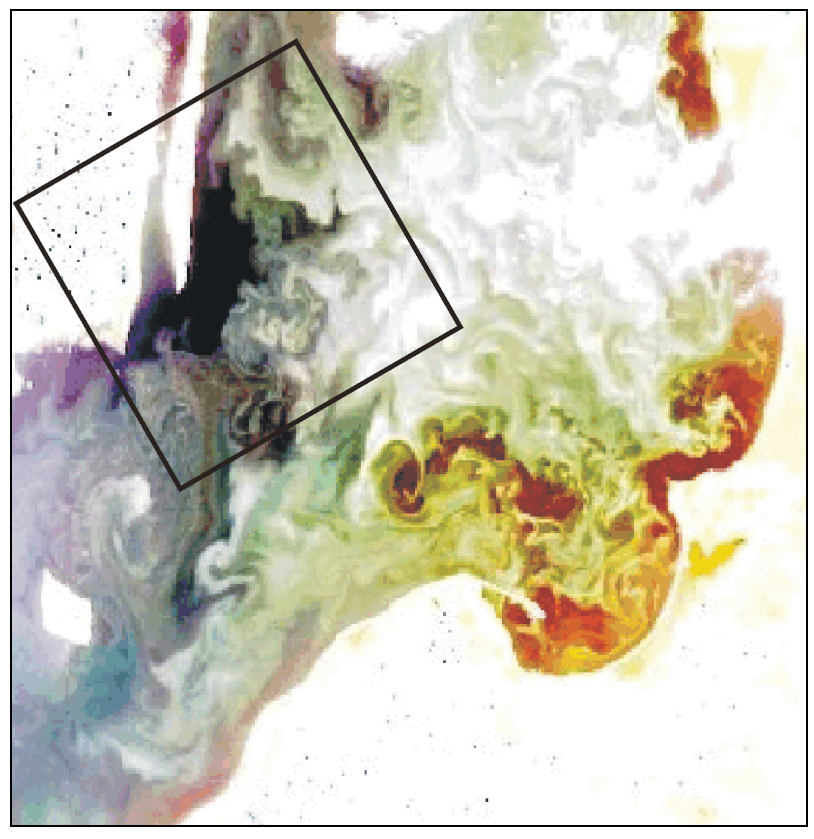

Figure 8: Images of the southern Baltic $\left(56^{\circ} 30^{\prime} \mathrm{N}, 17^{\circ} \mathrm{E}\right)$ acquired on July 28,1999 . (a) Radarsat image acquired at 16:14 UTC, size of the imaged area: $100 \times 100 \mathrm{~km}^{2}$; (b) SeaWiFS colour composite of the $670 \mathrm{~nm}, 555 \mathrm{~nm}$ and $490 \mathrm{~nm}$ channels (as RGB), acquired at 11:15 UTC, size of the imaged area: approximately $400 \times 400 \mathrm{~km}^{2}$. 